\title{
Landscape, Process and Power: Re-evaluating Traditional Environmental Knowledge
}

Serena Heckler, ed. 2009. Berghahn Books, New York. Pp. 304, 21 illustrations, bibliography, index. $\$ 95.00$

(hardback). ISBN 978-1-84545-549-1

Reviewed by Colleen Marie O’Brien ${ }^{1}$

Reviewer's Address: ${ }^{1}$ University of South Florida Department of Anthropology, Tampa, FL

Received: May $26^{\text {th }} 2010$

Published: September $6^{\text {th }} 2010$

Environmental knowledge and its various forms and appellations (ecological, indigenous, local, traditional) has been at the forefront of ethnobotany, ethnobiology, environmental anthropology, and related subdisciplines for the past several decades. Current debates both within and outside of academia focus on such questions as: How does environmental knowledge vary within a community and how is it learned and transmitted? How is knowledge lost or transformed in response to rapid global change? How do power, history, and context shape knowledge production and reproduction? And, who should have control over its use and applications? The edited volume Landscape, Process, and Power successfully captures the evolution of traditional environmental knowledge (TEK) studies and applications and serves as a guidepost for future directions in the field.

This volume is a diverse collection of applied, cognitive, critical, phenomenological, and political economy approaches to the study of TEK. Its contributors are an assemblage of academics and practitioners with backgrounds in environmental anthropology, ethnobotany, ecology, conservation, and international development. In Chapter One, Heckler explains the genesis of the book and its organization around the common emergent themes of landscape, process, and power. According to Heckler, after a 2004 panel on "TEK and Change" at the 9th International Congress of Ethnobiology, it became apparent that the way in which researchers were studying, discussing, and applying TEK was changing along with its content. This volume's goals are therefore to articulate the fluid character of knowledge resulting from people's daily engagement with the landscape around them and to illustrate the historical and political forces that have shaped and continue to influence TEK.
Volume 1:37-38

(C) 2010 Society of Ethnobiology

In Chapter Two, Zent presents a thorough genealogical review of TEK studies and describes the current cognitive dissonance in the field as a "sign of strength" (p. 20). According to Zent, much of the early work on TEK attempted to blur the lines between scientific and indigenous knowledge, so much so in fact, that at times environmental knowledge was entirely "severed from culturally situated practice" (p. 36). This compartmentalizing of knowledge raises social, political, ethical, and methodological concerns which are expanded upon in the following chapters. Alexiades discusses the commoditization of knowledge in Chapter Three, raising critical questions concerning how knowledge is used, represented, and appropriated as well as who benefits from its consumption. In Chapter Four, Carss et al. apply TEK to European conservation concerns by integrating local knowledge into fisheries and cormorant (Phalacrocorax carbo carbo or Phalacrocorax carbo sinensis) management, focusing on how power is distributed in such conflicts. In Chapter Five, Gilberthorpe explains how oil industry development has shaped environmental perceptions of land as well as gender relations in Papua New Guinea. In Chapter Six, Thomas challenges assumptions regarding indigenous people and conservation in his study on biological diversity and human disturbance in Papua New Guinea. Fujimoto looks at the ethnobotany of the Malo of Ethiopia in Chapter Seven, particularly their indirect uses of plants, which play important roles in transmitting agricultural knowledge. In Chapter Eight, Boissiere focuses on the transformation of identities and dynamics of knowledge among the Yali and Hupla, two ethnic groups who share the same territory in Holuwon, West Papua New Guinea. In Chapter Nine, Vermonden shifts from focusing on the content of TEK to discovering configurations of practice and interactions that lead to learning TEK in a 
fishing village in South Buton, Sulawesi. In Chapter Ten, Sillitoe revisits the long accepted theory of carrying capacity in the New Guinea highlands where the complexity of farming systems makes its application problematic. Rounding out the volume in Chapter Eleven, Kassam and Ganya demonstrate that knowledge is traditional but not static and that it can dynamically incorporate change by looking at the Gabra Oromo nomads of northern Kenya and how they have successfully adapted and transformed TEK to manage their rangelands.

One of the important contributions of this volume is that it engages with current scholarship on the effects of global environmental changes on local populations. Locals are portrayed not as victims of change but rather as active participants, transforming their practices in novel ways to meet new demands on resources. Kassam and Ganya are particularly successful at illustrating this point. Of course global changes such as those born out of development often prompt unanticipated consequences exemplified by Gillberthorpe's discussion on the Fasu's changing values and identity roles after the entrance of an oil company into the region where former land tenure practices have been transformed by the company's more static view of land ownership. In similar fashion, Thomas predicts that healthcare development in Hewa, Papua New Guinea could also indirectly threaten biodiversity through improved life expectancy, increased housing within close proximity to healthcare facilities, and through shortened fallow periods.

Another contribution of this volume is its focus on combined methodological approaches for studying TEK. Fujimoto's study highlights the complexities of knowledge systems and how easy it is to overlook information that may not be considered "knowledge" to locals or that is highly varied among actors in a given culture or community. For example, Fujimoto argues that the more subtle aspects of TEK are "so embedded in local TEK that farmers do not recognize it out of context" (p. 157) when describing his experience of studying indirect plant uses with the Malo of southwestern Ethiopia. Fujimoto used participant observation and unstructured interviews in order to discern subtle indirect plant-use practices such as using them as indicators of degraded fields or fertile soils. Boissiere uses a mixed method approach for looking at the transformation of identities and dynamics of knowledge-sharing among the Yali and Hupla, two ethnic groups who share the same territory in Holuwon, West Papua New Guinea. Through structured and unstructured interviews, participant observation, migration myth analysis, and in-depth ethnobotanical surveys, Boissiere discerns not only what is known about area plants but also gains a broader view about how this information is transmitted and maintained. By using a historical approach, he finds that subsistence and social organization of the two groups is nearly identical. However, by focusing on their myths, religion, and shamanism, there is further evidence of the Yali's predominance over the Hupla. Vermonden emphasizes the importance of process in learning TEK by investigating the socially situated transmission of fishing activities using a combination of participant observation and structured and unstructured interviews. In each of these cases the use of complementary methods adds clarity and context to the research.

Very few areas in this volume fall short because of its thorough coverage of the processual aspects of knowledge and how it is mediated through local landscapes and power relationships. However, since the premise of the volume is that knowledge is processual, a chapter focusing on generational change in TEK, particularly on children and knowledge acquisition, is missing. There is currently a paucity of published studies on how children learn TEK and whether changes in learning are contributing to knowledge loss.

Overall, this volume succeeds in its purpose to dislodge enduring western notions of TEK as static and to firmly center it within an analytical framework of landscape, process, and power. Much like TEK, the term 'landscape' has undergone a transformation of its own progressing beyond purely ecological concerns to incorporate historicity, movement, and past and present social relationships. The application of the term landscape to TEK is reflective of the interdisciplinary nature of environmental knowledge studies. As its subtitle, "Re-evaluating Traditional Environmental Knowledge," suggests, this volume challenges formerly accepted notions of TEK as a panacea for environmental problems, capable of being extracted, packaged, and conveniently exported to other settings and rather presents an alternative view on knowledge as embedded and contextualized within particular landscapes. The critical perspectives of the authors of this book would prompt lively discussion in the classroom, and the book's grounding in ethnographic detail and applications are of interest to both research academics and practitioners. 